\title{
Perspectivas da Ciência da Informação para o estudo do prontuário do paciente
}

\author{
Perspectives of Information Science for the study of patient records
}

\begin{abstract}
Fabrício Amadeu Gualdani
Mestrando no Programa de Pós-Graduação em Ciência da Informação da Universidade Estadual Paulista Júlio de Mesquita Filho - UNESP, campus de Marília, Brasil

E-mail: fabricio.gualdani@unesp.br https://orcid.org/0000-0001-7426-0831

Maria Cristiane Barbosa Galvão Doutora em Ciência da Informação pela Universidade de Brasília - UnB, Brasil. Professora Doutora da Faculdade de Medicina de Ribeirão Preto da Universidade de São Paulo - FMRP/USP, Brasil.

E-mail: mgalvao@usp.br https://orcid.org/0000-0003-3971-5743
\end{abstract}

\section{Resumo}

A Ciência da Informação tem por objetos de estudos a informação em seus diferentes suportes, o desenvolvimento e a aplicação de protocolos para a seleção, representação, organização, recuperação, disseminação e compreensão da informação, bem como a proposição e avaliação de serviços e produtos informacionais. Neste estudo, objetivouse compreender como esse campo tem estudado o objeto informacional prontuário do paciente. A metodologia empregada foi a revisão de literatura, adotando-se como critérios de inclusão estudos produzidos no Brasil, publicados em periódicos do campo da Ciência da Informação, sem delimitação de período. Dos 57 artigos científicos identificados na Base de Dados de Periódicos em Ciência da Informação (BRAPCI), 45 artigos foram selecionados de forma independente pelos autores. Como resultado, observou-se que os estudos brasileiros sobre o prontuário do paciente contemplam oito perspectivas, quais sejam: cultural, ético-jurídica, educacional, filosófica, conceitual, arquivística, tecnológica e gerencial. Conclui-se que as abordagens mapeadas não excluem outras possibilidades de sistematização, mas evidenciam a riqueza do prontuário do paciente como objeto de estudo e evidenciam a dimensão colaborativa e os múltiplos diálogos da Ciência da Informação com o campo da Saúde.

Palavras-chave: Prontuário do paciente. Ciência da Informação. Saúde. Revisão de literatura. Brasil.

\begin{abstract}
Information Science studies information in its different supports, the development and application of protocols for selecting, representing, organizing, recovering, disseminating and understanding information, as well as the proposition and evaluation of informational products and services. In this study, the objective was to understand how this field has studied the patient record as an informational object. The methodology used was the literature review, adopting as inclusion criteria studies produced in Brazil, published in journals in the field of Information Science, without delimiting the period. Of 57 scientific articles identified in the Database of Journals in Information Science (BRAPCI), 45 articles were selected independently by the authors. As a result, it was observed that Brazilian studies on the patient record contemplate eight perspectives, namely: cultural, ethical-legal, educational, philosophical, conceptual, archival, technological, and managerial. In conclusion, without excluding other possibilities of systematization, these perspectives show the richness of the patient record as an object of study, as well as the multiple dialogues and collaborative dimension between Information Science and the Health field.
\end{abstract}

Keywords: Patient record. Information Science. Health. Literature review. Brazil. 


\section{Introdução}

A Ciência da Informação tem por objeto de estudo a informação e, independentemente do suporte físico ou do formato em que se encontra a informação, busca desenvolver e aplicar protocolos para a seleção, representação, organização, recuperação, disseminação e compreensão da informação, bem como se preocupa com uma multiplicidade de serviços e produtos informacionais. Estudos clássicos da área ressaltam ser parte da natureza dessa ciência o diálogo e ações colaborativas com diferentes áreas do conhecimento (SARACEVIC, 1995, 1996; HOLLAND, 2008; ARAÚJO, 2014).

Le Coadic, em seu trabalho de 1996, apresenta um mapa norteador de áreas que estiveram no cerne da Ciência da Informação, onde ressalta o papel da Biblioteconomia, da Documentação, da Museoeconomia (nos termos do autor), da Arquivística, do Jornalismo, bem como da Economia, do Direito, da Política, da Sociologia, da Etnologia, da Psicologia, da Ciência Cognitiva, das Telecomunicações, da Eletrônica, da Linguística, da Informática, da História, da Epistemologia, da Filosofia, da Lógica, da Estatística e da Matemática.

Considerando a proposição de que a Ciência da Informação é um campo colaborativo que dialoga, influencia e é influenciada por vários campos, o objetivo deste trabalho consiste em averiguar como essa ciência tem estudado o prontuário do paciente, documento historicamente produzido no campo da saúde e que contém informações retrospectivas (fatos ocorridos), informações correntes (fatos que estão ocorrendo) e informações prospectivas (fatos que acontecerão) sobre um paciente, mas que também é um documento que comporta informações relevantes para os processos de trabalho e gestão dos serviços de saúde, para o desenvolvimento de políticas institucionais e políticas públicas, bem como um documento de valiosa importância para a pesquisa em saúde (GALVÃO; RICARTE, 2012).

Logo, sistematizar as relações criadas e estabelecidas entre a Ciência da Informação e o objeto prontuário do paciente pode trazer novas descobertas sobre como os pesquisadores e profissionais que atuam na área têm priorizado essa importante fonte de informação do campo da saúde e quais contribuições já construíram sobre esse documento. 


\section{Metodologia}

Optou-se pela elaboração de uma pesquisa exploratória, com foco na revisão de literatura. Essa abordagem possibilita compreender melhor a temática estudada, sem uma prévia delimitação de ângulos ou aspectos a serem observados. Por outro lado, fornece uma base para que futuras pesquisas possam se aprofundar em aspectos que por ventura forem sistematizados. Já a revisão de literatura apresenta, critica e compartilha o conhecimento produzido em estudos prévios, destacando conceitos, procedimentos, resultados, discussões e conclusões relevantes, permitindo apresentar um diálogo harmonioso entre os trabalhos científicos já publicados de outros autores (PRODANOV; FREITAS, 2013).

Para a elaboração desta revisão, os critérios de inclusão dos estudos foram: ser um estudo publicado no Brasil, produzido em qualquer período, que abordasse o tema prontuário do paciente considerando a perspectiva da Ciência da Informação. Como exemplo de estudo incluído na revisão pode ser citado "A ética e prontuário de paciente" (ARAUJO, 2018). Empregaram-se, ainda, como critérios de exclusão estudos do campo da Saúde que usavam prontuários para o levantamento de dados epidemiológicos, bem como estudos voltados para a informação que apenas citavam o prontuário em algum exemplo, mas que não tinham a temática principal voltada para este assunto. Como exemplo de estudo excluído pode ser mencionado o trabalho "Curadoria digital: uma área em expansão" (SIEBRA, 2019).

A partir dos critérios de inclusão e exclusão estabelecidos, acessou-se a base de dados Scientific Electronic Library Online (Scielo) por meio de múltiplas estratégias de busca, mas os resultados obtidos não se mostraram significativos para análise. Acessou-se, em agosto de 2020, a Base de Dados Referenciais de Artigos de Periódicos em Ciência da Informação (BRAPCI). Nesta base, optou-se pelo emprego de estratégias de busca amplas. Assim, utilizouse o termo "prontuário*" no campo "título, palavra-chave e resumo" que resultou na recuperação de 57 referências bibliográficas. A seguir foi realizada uma segunda busca na referida base de dados, empregando-se os termos "registro*" e "saúde" no campo "título, palavra-chave e resumo", o que resultou na recuperação das mesmas referências. Após a retirada dos estudos duplicados, da análise dos títulos e dos resumos dos estudos encontrados, foram selecionados 45 estudos, produzidos entre 2006 a 2020, para serem analisados e sistematizados. 
No processo de análise, foram extraídos dos textos seus objetivos, suas metodologias, seus resultados e suas conclusões. A partir dessa extração, os estudos foram analisados de forma independente por dois pesquisadores com o objetivo de identificar quais eram as perspectivas priorizadas. Para tanto, cada pesquisador criou livremente seu próprio conjunto de temáticas. Finalizado este processo, os pesquisadores se reuniram e compararam suas análises, observando pontos de concordância e discordância. Notou-se, então, que as análises independentes convergiam conceitualmente. Obviamente que, por se tratar de um estudo qualitativo e exploratório, a sistematização proposta é de caráter empírico-pragmático, constituindo-se como uma tentativa de organizar uma dada realidade para aumentar sua compreensão, não possuindo a pretensão de seguir princípios classificatórios aristotélicos, conforme explana Araújo (2006).

\section{Resultados}

No processo de análise dos 45 estudos selecionados observou-se que os prontuários de pacientes são estudados, no contexto da Ciência da Informação, no período de 2006 a 2020, segundo, pelo menos, oito perspectivas. São elas: a perspectiva cultural, a perspectiva éticojurídica, a perspectiva educacional, a perspectiva filosófica, a perspectiva conceitual, a perspectiva arquivística, a perspectiva tecnológica e a perspectiva gerencial. Aqui faz-se necessário esclarecer que um estudo pode apresentar mais de uma perspectiva, quando, por exemplo, foca os aspectos culturais relacionando-os com aspectos legais, ou quando foca em uma tecnologia específica para resolver uma problemática arquivística, e assim por diante. Logo, mais que se pensar em perspectivas que se excluem, são perspectivas que dialogam, se entrelaçam e se relacionam formando um tecido de conhecimento. Isso posto, apresentar-se-ão essas perspectivas de modo que fiquem mais explícitas para o leitor. 


\subsection{Perspectiva cultural}

A perspectiva cultural analisa o prontuário do paciente como patrimônio documental, cultural e objeto de preservação da memória. Nesta perspectiva, o prontuário do paciente é entendido como um documento de extrema importância para a qualidade do atendimento prestado ao paciente, para o desenvolvimento da pesquisa médica, administrativa, jurídica e científica-acadêmica, e que possibilita a recuperação da informação relacionada aos serviços prestados e aos tratamentos oferecidos (LUNARDELLI; TONELLO; MOLINA, 2014).

Além disso, é o prontuário é entendido como um valioso documento de constituição da memória da saúde da população e das instituições de saúde, reunindo uma coleção de documentos que deve ser preservada por ser a representação da saúde de grupos sociais pertencentes a uma sociedade ou a uma região. Assim, é o reflexo das condições históricas e culturais de um determinado tempo, do mesmo modo que também representa os investimentos e políticas públicas em saúde realizados em uma época (CRUZ; FLORES; GARCIA, 2011).

Adicionalmente, entende-se aqui que os arquivos hospitalares, responsáveis pela gestão documental e, portanto, pelos prontuários de paciente, possuem um papel decisivo para a compreensão do avanço científico das técnicas, práticas, políticas e metodologias desenvolvidas no campo da saúde (RAMOS, 2018).

\subsection{Perspectiva ético-jurídica}

A perspectiva ético-jurídica analisa questões relacionadas ao acesso, utilização e sigilo das informações disponibilizadas no prontuário do paciente, segundo as normas e legislações vigentes.

Já em 2013, Tonello, Nunes e Panaro observaram que a Lei de Acesso à Informação, embora tenha sido criada com a finalidade de garantir o acesso às informações, restringe o acesso aos documentos sigilosos relacionados à honra e a imagem das pessoas, como é o caso do prontuário do paciente, esclarecendo ainda que essa Lei, em seu capítulo IV seção V, também responsabiliza quem usou as informações sigilosas de forma indevida.

Cruz (2015) questiona o prazo de 20 anos após o último registro para eliminação do prontuário do paciente em suporte papel estabelecido pela resolução 1821/2007 do Conselho Federal de Medicina, pois entende que é um tempo insuficiente para atender as necessidades 
dos usuários brasileiros, já que esse documento muitas vezes é empregado para identificar paternidade, pagamento de seguros de vida, de saúde ou trabalhista, pesquisa acadêmica, bem como para a análise, obtenção e uso de verbas pelas instituições de saúde.

Alcântara e Rached (2016) acrescentam que o acesso às informações dos prontuários de paciente, com a devida manutenção de seu sigilo, demanda o desenvolvimento e a implementação de serviços informacionais inovadores com responsabilidade e ética, qualificação dos atores envolvidos nos processos informacionais, bem como um ambiente de trabalho excelente, confortável, moderno e seguro.

Araujo (2018) complementa que o prontuário do paciente requer um tratamento sigiloso, com acesso limitado, tanto no momento de sua produção pelos profissionais de saúde como durante a sua guarda pelo serviço de arquivo médico.

Araujo e Blattmann (2018) ressaltam que há pesquisadores que, quando utilizam o prontuário do paciente como fonte de pesquisa, não se sentem obrigados a solicitar autorização do paciente, por entenderem que esse documento é uma fonte secundária, ou seja, as informações registradas são apenas dados, e sendo assim a instituição responsável pela guarda desse documento tem que permitir o acesso ao seu conteúdo informacional. Logo, nota-se ainda um desconhecimento dos aspectos legais relacionados ao prontuário do paciente.

Araujo e Mota (2020) esclarecem que os prontuários de pacientes possuem informações que são de exclusividade do paciente e da equipe de saúde que o acompanha. Assim, o pesquisador terá que solicitar autorização ao paciente para que possa ter acesso às informações contidas no prontuário. As autoras entendem ainda que o prontuário é uma fonte primária de informação e, levando em consideração a ética em pesquisa com seres humanos, haverá sempre a necessidade da concordância do participante envolvido na pesquisa para que seu prontuário seja acessado para fins de pesquisa científica.

Ricarte (2020), ao analisar a privacidade em sistemas nacionais de prontuários eletrônicos, observa que por parte dos pacientes existe o receio de acesso inapropriado aos seus dados, roubo de identidade e uso inadequado de informação por empresas de seguro ou empregadores. Assim, as questões sobre privacidade dos prontuários eletrônicos de saúde demandam que haja um posicionamento com maior nitidez, por parte dos governos, sobre a garantia da confidencialidade dos dados e seus usos secundários por diferentes atores sociais. 


\subsection{Perspectiva educacional}

A perspectiva educacional analisa o prontuário do paciente como objeto informacional a ser integrado nos processos de ensino-aprendizagem.

Mota (2006), focando na competência informacional, ressalta que os profissionais de saúde precisam estar abertos ao aprendizado para que possam ser agentes transformadores de si próprios e do mundo que os cercam. Destaca que a equipe multiprofissional, analisada em seu estudo, apresenta uma alta capacidade de identificar as vantagens e desvantagens do uso do prontuário eletrônico do paciente, bem como o grande potencial desses profissionais para explorar todas as funcionalidades desse documento.

Galvão e Ricarte (2011) destacam que, dada a complexidade do prontuário do paciente, é preciso pensar em estratégias coletivas de ação para o seu estudo no contexto da Ciência da Informação que envolvam os programas de pós-graduação e os cursos de graduação, capacitação continuada de profissionais, estabelecimento de políticas nacionais referentes à pesquisa em informação em saúde, e a criação de grupos de pesquisa e grupos de interesse especial no prontuário do paciente que extrapolem a disciplinaridade.

Já Bahia (2016) desenvolveu um estudo que relata os aspectos didáticos da disciplina de documentação em unidades de saúde ministrada no curso de Graduação em Arquivologia na Universidade Federal de Santa Catarina, destacando que as aulas práticas envolvendo o estudo do prontuário são fundamentais para o desenvolvimento e aprendizado de cada estudante, que futuramente exercerá a profissão de arquivista, e que é essencial a participação desse profissional no processo decisório e de planejamento em um arquivo médico, bem como em todos os processos relacionados à conservação, utilização, recuperação e até mesmo descarte dos prontuários dentro de uma unidade de saúde. 


\subsection{Perspectiva filosófica}

A perspectiva filosófica analisa o prontuário do paciente do ponto de vista filosófico, epistemológico e social. Almeida e Andrade (2014), por exemplo, desenvolveram um estudo baseado na teoria dos três mundos de Karl Popper, pois entendem que, por meio dessa teoria, é possível distinguir diferentes tipos de dados e realidades presentes no prontuário do paciente.

Com base nas ideias de Michel Foucault, Lima e Sanches Neto (2017) e Sanches Neto e Lima $(2016$; 2017) observaram que o prontuário do paciente é um dispositivo de poder que explicita uma visão marginalizada sobre determinados indivíduos, como é o caso dos pacientes psiquiátricos. Acrescentam que o documento médico pode exercer uma função discriminatória e segregadora, pois as informações presentes nesse documento podem influenciar ou mesmo afetar a autocrítica, visão e percepção de um indivíduo sobre si mesmo. Assim, por exemplo, um profissional da saúde, ao diagnosticar um paciente como "louco ou anormal", está enquadrando o paciente em uma imagem social relacionada a ideias como sujeira, doença, repúdio, afastamento, perigo. Logo, o registro clínico, ao mesmo tempo que possui um embasamento científico, traz questões éticas, sociais e morais inseridas na sociedade que podem gerar preconceitos discriminações e julgamentos sobre o paciente.

\subsection{Perspectiva conceitual}

A perspectiva conceitual busca mapear as principais características do conceito de prontuário do paciente, em suporte papel ou em suporte eletrônico. Cabe esclarecer que grande parte dos autores estudados teve a preocupação em conceituar o termo "prontuário do paciente". Logo, os autores citados nesta perspectiva trazem algumas das diversas preocupações encontradas no processo de explicitação conceitual desse termo.

Pinto (2006) explica que o prontuário do paciente é um documento valioso para a utilização de pesquisadores, tanto no campo da saúde como em outros setores do conhecimento, devido a suas informações, que possibilitam a identificação de padrões em situações específicas relacionadas a problemas de saúde, descobertas de novas patologias e mesmo detalhes mais precisos sobre as enfermidades já existentes, graças a um bom registro das informações do paciente que permitem mapear essas situações. Esclarece que o prontuário do paciente é um documento que demanda uma produção adequada e um sistema de recuperação da informação 
para a sua devida utilização. Ressalta a autora que o prontuário do paciente é um documento que deve ser explorado pelos profissionais da informação.

Albergaria et al. (2016) analisaram o prontuário do paciente considerando a flexibilidade, a padronização, a estrutura e a facilidade de interação, reiterando que os sistemas de prontuários eletrônicos são plataformas de extrema importância tanto para profissionais da saúde como para os pacientes. Assim, a organização e padronização dos dados são exigências indispensáveis para as informações de tais sistemas, que podem ser utilizadas para melhorar o atendimento dos profissionais e apoiar estudos voltados a toda a população.

De forma complementar, Galvão e Ricarte (2017) esclarecem que não se pode compreender o prontuário do paciente sem o entendimento do sistema de saúde, isto é, sem conhecer o contexto em que ele é produzido, organizado e utilizado. Como o sistema de saúde brasileiro prioriza as condições físicas, psicológicas e sociais dos indivíduos durante a assistência em saúde, o prontuário deve contemplar toda essa gama de conteúdos informacionais sobre o paciente. Logo, é importante que pesquisadores e profissionais que atuam na Ciência da Informação compreendam a relação entre o sistema de saúde e o prontuário do paciente.

Kawakami, Lunardelli e Vechiatto (2017) buscaram compreender os aspectos relacionados à usabilidade do prontuário eletrônico do paciente, enquanto Santos e Damian (2017) buscaram compreender a veracidade, a confiabilidade, a padronização e a organização das informações presentes nos prontuários. Santos e Damian (2017) destacam que todos os problemas relacionados ao preenchimento, organização, armazenamento e recuperação das informações podem continuar exatamente iguais mesmo que o prontuário do paciente esteja em suporte eletrônico. Para evitar todos esses transtornos, são necessárias a valorização das bases humanas de informação e a construção de políticas e diretrizes internas que respeitem uma padronização quanto ao uso e preenchimento desse documento, tornando-o assim uma ferramenta que produz informação para auxílio nas tomadas de decisões.

Souza e Souza (2018) destacam que muitas unidades de saúde ainda não implantaram o prontuário eletrônico do paciente com a certificação digital. Logo, a utilização do prontuário do paciente em suporte papel ainda é uma prática extremamente utilizada. 


\subsection{Perspectiva arquivística}

A perspectiva arquivística prioriza o prontuário do paciente como documento arquivístico. Novamente, cabe esclarecer que muitos autores tiveram uma preocupação em compreender o prontuário do paciente em sua natureza arquivística. Logo, os autores citados nesta perspectiva ilustram, em alguma medida, essa preocupação.

Molina e Lunardelli (2010) realizaram um estudo abordando os diferentes aspectos e situações envolvendo o prontuário do paciente, disponível em seus dois suportes, em papel e em formato digital. Levantam as dificuldades quanto à implementação e uso do prontuário eletrônico, as técnicas, métodos e práticas que conectam o campo da arquivologia a esse documento, e ressaltam que o número de profissionais devidamente qualificados tecnicamente e profissionalmente no ramo da arquivística atuando em organizações da área da saúde é inexpressivo.

Zilli Júnior e Pinto (2014), considerando a arquivometria, buscaram mensurar o tempo e apresentar as etapas do processo de digitalização de prontuários, incluindo as fases de protocolo, preparo, digitalização, controle de qualidade, indexação e redigitalização.

Leite e Sousa (2015) analisaram a organização e o funcionamento do arquivo de prontuários em suporte papel de uma unidade de saúde da família, identificando as barreiras que interferem na recuperação da informação e concluindo que são necessárias mudanças estruturais, de recursos humanos e materiais do arquivo de prontuários. Para tanto propõem: aquisição de mobiliário, pastas e envelopes, adoção de padronização do método de arquivamento numérico, da qual todos os prontuários pertencentes aos integrantes de cada família sejam agrupados em um único envelope com um índice alfabético, e um melhor treinamento e preparação de recepcionista quanto às práticas, técnicas e métodos arquivísticos para facilitar a compreensão sobre o funcionamento da guarda, conservação e preservação de documentos.

França, Souza, Chaves (2016) ressaltam que o prontuário do paciente possui um valor administrativo e, devido ao fato de ser por definição um documento de natureza arquivística, deve obedecer a diretrizes relacionadas com o seu armazenamento, preservação e utilização exigidas em lei. 
Jappe e Cruz (2016) ressaltam que o prontuário do paciente pode ser considerado a princípio como um documento arquivístico. Para isso, são necessárias medidas que impeçam qualquer tipo de manipulação ou alteração indevida ou não autorizada desse documento.

Mais recentemente, Cunha et al. (2018) destacam que o prontuário eletrônico do paciente demanda um comprometimento com a manutenção e preservação de uma cadeia de custódia desde a produção até a preservação. Assim, torna-se necessário uma gestão arquivística dos documentos em formato digital, com o objetivo de atender as demandas da assistência em saúde.

Santos, Vitoriano e Damian (2019) entendem que o prontuário do paciente consiste em uma documentação essencial para a formulação dos sistemas de informação em saúde, sendo responsável pela produção e disponibilização diária de uma grande quantidade de informação que representa a trajetória de vida relativa à saúde de um número muito grande de pessoas. Entendem que por meio do auxílio técnico dos profissionais da informação, principalmente o arquivista, será possível um fortalecimento da cultura informacional da unidade de saúde.

\subsection{Perspectiva gerencial}

A perspectiva gerencial analisa o prontuário do paciente segundo uma ótica institucional, considerando a gestão documental e a existência de comissões de avaliações nas instituições de saúde.

Ferreira, Fidelis e Lima (2013) analisaram a gestão documental, incluindo as atividades de produção, classificação, avaliação e arquivamento dos documentos, fluxo informacional, e a rotina administrativa de um hospital. Concluíram que não é concebível o funcionamento de uma instituição hospitalar sem uma política de gestão documental, uma vez que a avaliação qualitativa do serviço prestado só é possível por meio do acesso às informações que são produzidas na instituição. Além disso, os dados gerados nos diversos setores do hospital, quando relacionados entre si, transformam-se em instrumentos estratégicos úteis para a avaliação da assistência prestada, quantidade de recursos envolvidos e controle dos custos gerados na concepção e dispensação de seus serviços.

Oliveira e Cunha (2014) destacam a importância das comissões de avaliações de documentos e de revisão de prontuários do paciente em serviços de saúde, muitas das quais não 
estão institucionalizadas e nem possuem procedimentos estabelecidos para que suas atividades sejam realizadas.

Silva (2016) avaliou os métodos de conservação, digitalização e microfilmagem de prontuários de pacientes em um hospital de emergência e observou que a instituição deveria escolher métodos mais modernos e seguros de conservação como a digitalização e a microfilmagem para organizar de forma padronizada a sua documentação, bem como deveria criar formalmente uma Comissão Permanente de Avaliação de Documentos que garanta legitimidade e autoridade à equipe responsável e à comissão de revisão de prontuários.

\subsection{Perspectiva tecnológica}

A perspectiva tecnológica analisa ferramentas e metodologias que, aplicadas ao prontuário do paciente, buscam melhorar sua qualidade, incluindo ferramentas de processamento de texto, de recuperação da informação, de segurança da informação, bem como ferramentas ou produtos terminológicos com foco no aperfeiçoamento do registro informacional.

Soares, Borges e Pinto (2010), por exemplo, evidenciam que é possível aplicar a categorização no tratamento, organização, representação, recuperação e a gestão de informações no contexto dos prontuários do paciente. Entretanto, ainda assim é possível identificar alguns problemas para se estabelecer a categorização, sendo um deles o uso de duas linguagens adotadas na elaboração desse documento, as linguagens de especialidades (terminológicas) utilizadas pelos profissionais de saúde e a linguagem coloquial dos pacientes que, ao se encontrarem, proporcionam falhas na comunicação, sendo necessário a transposição de uma linguagem para outra, do coloquial para o científico e do científico para o coloquial. Portanto, no tratamento informacional desses documentos, nenhuma dessas linguagens deve ser desconsiderada.

Também preocupados com a linguagem, Mendonça, Cardoso e Drumond (2010) realizaram um estudo com o objetivo de desenvolver uma ferramenta de apoio para o correto preenchimento das declarações de óbito, representado por meio de uma ontologia de aplicação desenvolvida com a participação de profissionais de saúde especialistas no domínio de mortalidade. 
Meneses, Raulino Neto e Girão (2013) realizaram um estudo com o intuito de discutir o conceito de arquitetura da informação como uma ferramenta de mediação e acesso aos conteúdos registrados no prontuário do paciente, com a organização da informação centrada no usuário. Entendem que seja possível aplicar a arquitetura da informação na organização do prontuário, levando em conta a espacialidade da informação, a função (acessibilidade e fluxo), a estética (padronização de cabeçalhos e atualização) e a solidez (confiabilidade, segurança, confidencialidade).

França, Pinto e Bagot (2017) buscam compreender quais são as implicações da falta de padronizações das siglas, acrônimos, abreviaturas e símbolos empregados no prontuário do paciente, especificamente nos resumos de alta, concluindo que a representação das siglas, acrônimos, abreviaturas e símbolos por especialidade médica auxiliam na compreensão desses termos de acordo com o contexto no qual foi empregado, facilitando a comunicação e recuperação da informação. Logo, é preciso elaborar fontes terminológicas padronizadas para o preenchimento dos campos do prontuário do paciente.

De forma semelhante, Santos (2018) entende que, para que um registro eletrônico em saúde possa ser utilizado, é necessário que exista compatibilidade entre as informações. No entanto, a padronização de registros e informações na área da saúde ainda é um assunto pendente no Brasil.

Souza e Almeida (2019) esclarecem que a maioria das informações registradas nos prontuários de pacientes são dados não estruturados, o que torna muito mais difícil a sua utilização para fins de pesquisa clínica. Assim, a partir de técnicas de mineração de textos, propõem a conexão entre os termos registradas no prontuário e as terminologias de referência em saúde. Carvalho (2018) também investigou a recuperação de informações e descoberta de conhecimento oriundo de informações provenientes de sistemas de saúde por meio de ferramentas de mineração de dados.

Silva, Sousa e Pinto (2018) observam a convergência entre os estudos da arquitetura da informação pervasiva e os registros eletrônicos em saúde, porém destacam a necessidade de novas pesquisas e debates sobre o assunto.

Moraes (2018) discutiu os processos de gerenciamento da qualidade e segurança das informações do paciente, concluindo que o padrão de Gestão de Informação e Comunicação do Manual Brasileiro de Acreditação para Organizações Prestadoras de Serviços de Saúde aborda 
de forma abrangente e profunda a questão da qualidade e segurança das informações e documentos gerados pela assistência do paciente/cliente.

Adicionalmente, Teixeira e Almeida (2019a, 2019b) reconhecem que um dos maiores desafios para o campo da saúde é a dificuldade de integração e de interoperabilidade entre os diversos registros de saúde dispersos em diferentes sistemas, espalhados por diferentes regiões geográficas e temporais, e também ressaltam metodologias de integração tendo por base as terminologias de referência em saúde.

Galvão e Ricarte (2019) entendem que existe um histórico de fragmentação dos sistemas de informações em saúde ocasionado pelas mais diversas iniciativas locais, regionais e nacionais de implantação de tecnologias de informação e comunicação. Devido a esse fato, vários países têm buscado soluções que permitam a interoperabilidade entre os sistemas já existentes ou uma proposta de sistemas únicos para a coleta de dados clínicos em escala nacional. Contudo, destacam que as mudanças tecnológicas relacionadas ao prontuário do paciente também podem alterar as tradicionais relações de poder, geralmente centradas nos médicos, e demandam uma completa revisão dos processos de trabalho na assistência em saúde.

\section{Conclusão}

O prontuário do paciente congrega informações produzidas, em suporte papel ou em suporte eletrônico, pela equipe multiprofissional de saúde, contemplando conteúdos referentes ao estado de saúde física, mental e todas as condições sociais vivenciadas por um paciente. Este trabalho mapeou as perspectivas que a Ciência da Informação tem empregado ao estudar o prontuário do paciente, conforme apresentado na Figura 1, evidenciando que a dimensão colaborativa desse campo traz contribuições a todo o ciclo informacional de produção desse documento, abarcando discussões que vão desde a produção do registro clínico, passando por sua organização, padronização, recuperação, disponibilização, utilização dos dados, bem como considerando dimensões humanísticas, culturais, sociais, éticas, filosóficas, educacionais, terminológicas, arquivísticas, tecnológicas, jurídicas e gerenciais. 
Figura 1 - Perspectivas da Ciência da Informação sobre o prontuário do paciente

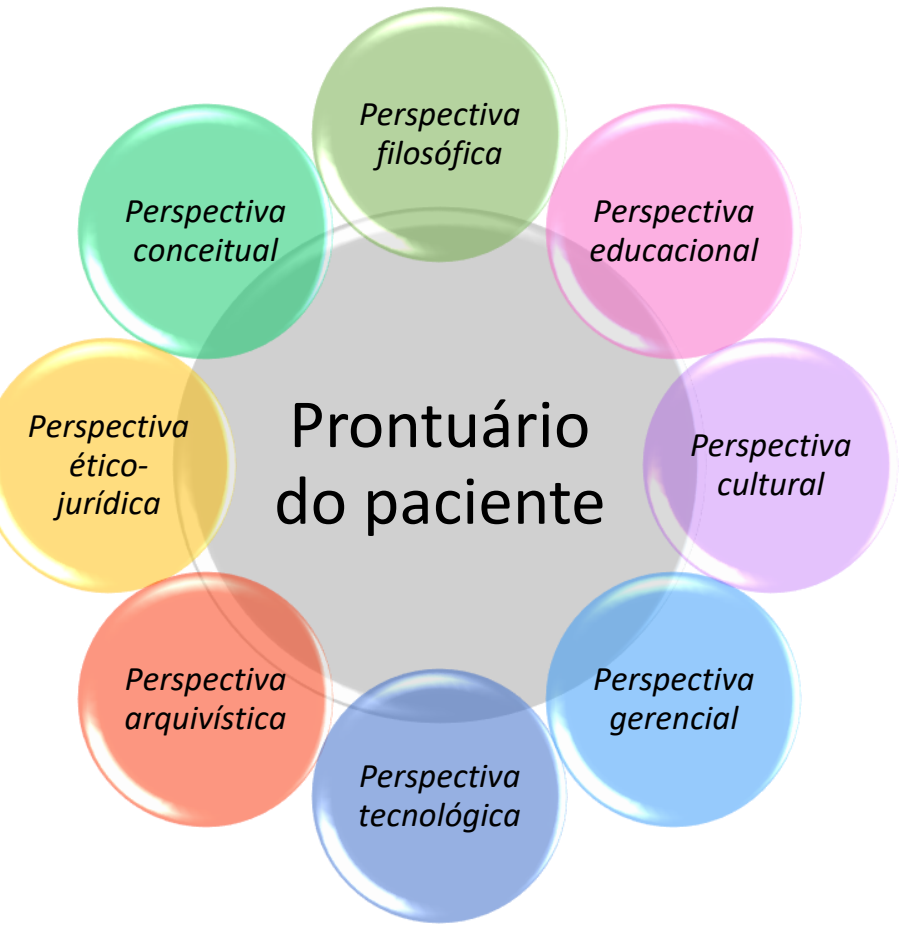

Fonte: Elaborado pelos autores

Finalmente, imagina-se que esta pesquisa permitirá o desenvolvimento futuro de uma série de novos estudos voltados para: a construção de critérios que caracterizem mais detalhadamente cada uma das perspectivas apresentadas; o aprofundamento de cada uma das perspectivas explicitadas; a reprodução dessa sistematização em novos cenários nacionais ou em análises comparativas entre diferentes países ou momentos históricos. 


\section{Referências}

ALBERGARIA, E. T. et al. Identificando propriedades essenciais de registros eletrônicos de saúde. AtoZ: Novas Práticas em Informação e Conhecimento, Curitiba, v. 5, n. 1, p. 33-43, 2016. Disponível em: http://www.brapci.inf.br/index.php/res/v/15537. Acesso em: 16 ago. 2020.

ALCÂNTARA, T. S.; RACHED, C. D. A. O gerenciamento do sigilo das informações do prontuário eletrônico em uma instituição hospitalar de S. Paulo. Prisma.com, Porto, n. 30, p. 6694, 2016. Disponível em: http://www.brapci.inf.br/index.php/res/v/71836. Acesso em: 16 ago. 2020.

ALMEIDA, M. B.; ANDRADE, A. Q. Organização da informação em prontuários de pacientes: uma abordagem popperiana. Informação \& Tecnologia, Marília, v. 1, n. 1, p. 29-41, 2014. Disponível em: http://www.brapci.inf.br/index.php/res/v/41297. Acesso em: 16 ago. 2020.

ARAÚJO, C. A. V. O que é Ciência da Informação? Informação \& Informação, Londrina, v. 19, n. 1, p. 01-30, dez. 2014. Disponível em:

http://www.uel.br/revistas/uel/index.php/informacao/article/view/15958. Acesso em: 03 nov. 2020.

ARAÚJO, C. A. V. Fundamentos teóricos da classificação. Encontros Bibli: Revista Eletrônica de Biblioteconomia e Ciência da Informação, Florianópolis, v. 11, n. 22, p. 117-140, 2006.

Disponível em: https://periodicos.ufsc.br/index.php/eb/article/view/1518-

2924.2006v11n22p117/0. Acesso em: 06 ago. 2020.

ARAUJO, N. C. A ética e prontuário de paciente. Pesquisa Brasileira em Ciência da

Informação e Biblioteconomia, João Pessoa, v. 13, n. 1, 2018. Disponível em:

http://www.brapci.inf.br/index.php/res/v/26598. Acesso em: 16 ago. 2020.

ARAUJO, N. C.; BLATTMANN, U. Prontuário do paciente: questões éticas na pesquisa. In: ENCONTRO NACIONAL DE PESQUISA EM CIÊNCIA DA INFORMAÇÃO, 19., 2018, Londrina. [Anais...]. Londrina: ANCIB: UEL, 2018. Disponível em: http://www.brapci.inf.br/index.php/res/v/102290. Acesso em: 16 ago. 2020.

ARAUJO, N. C.; MOTA, F. R. L. Prontuário de paciente. Informação em Pauta, Fortaleza, v. 5, n. Especial 1, p. 52-67, 2020. Disponível em: http://hdl.handle.net/20.500.11959/brapci/136639. Acesso em: 06 ago. 2020.

BAHIA, E. M. S. Conhecimento, inovação e documentação em unidades de saúde. BIBLOS Revista do Instituto de Ciências Humanas e da Informação, Rio Grande, v. 30, n. 1, p. 142 155, 2016. Disponível em: http://www.brapci.inf.br/index.php/res/v/22598. Acesso em: 16 ago. 2020.

CARVALHO, R. C. Aplicação de mineração de dados em informações oriundas de prontuários de paciente. Informação em Pauta, Fortaleza, v. 3, p. 161-181, 2018. Disponível em: http://www.brapci.inf.br/index.php/res/v/106569. Acesso em: 16 ago. 2020.

CRUZ, J. A. Informações em saúde: um estudo da legislação brasileira. Ponto de Acesso,

Salvador, v. 9, n. 1, p. 111-121, 2015. Disponível em:

http://www.brapci.inf.br/index.php/res/v/81847. Acesso em: 16 ago. 2020.

InCID: R. Ci. Inf. e Doc., Ribeirão Preto, v. 11, n. 2, p. 142-161, set. 2020/fev. 2021. 
CRUZ, Jorge Alberto Soares; FLORES, Daniel; GARCIA, Olga Maria Correa. O prontuário eletrônico de paciente (PEP) como memória, patrimônio documental e cultural. Em Questão, Porto Alegre, v. 17, n. 2, p. 91-99, 2011. Disponível em:

https://seer.ufrgs.br/EmQuestao/article/view/21490/14307. Acesso em: 16 ago. 2020.

CUNHA, F. J. A. P. et al. Espécies e tipologias documentais no contexto dos registros eletrônicos em saúde. In: ENCONTRO NACIONAL DE PESQUISA EM CIÊNCIA DA INFORMAÇÃO, 19., 2018, Londrina. [Anais...]. Londrina: ANCIB: UEL, 2018. Disponível em: http://www.brapci.inf.br/index.php/res/v/103847. Acesso em: 16 ago. 2020.

FERREIRA, J. S.; FIDELIS, M. B.; LIMA, M. J. C. O fluxo de informação nas instituições hospitalares e a gestão de documentos. Ágora, Florianópolis, v. 23, n. 47, p. 99-117, 2013. Disponível em: http://www.brapci.inf.br/index.php/res/v/12938. Acesso em: 16 ago. 2020.

FRANÇA, F. S.; PINTO, V. B.; BAGOT, R. E. Uso da redução léxica e símbolos na redação de resumos de alta em prontuário do paciente. In: ENCONTRO NACIONAL DE PESQUISA EM CIÊNCIA DA INFORMAÇÃO, 18., 2017, Marília. [Anais....]. Marília: ANCIB: UNESP, 2017. Disponível em: http://www.brapci.inf.br/index.php/res/v/105484. Acesso em: 02 maio. 2019.

FRANÇA, H. E. C.; SOUZA, J. F.; CHAVES, E. B. Tratamento arquivístico do prontuário do paciente: um contraponto terminológico a Galvão, Ferreira e Ricarte. Revista Analisando em Ciência da Informação, João Pessoa, v. 4, n. especial, 2016. Disponível em: http://www.brapci.inf.br/index.php/res/v/80962. Acesso em: 16 ago. 2020.

GALVÃO, M. C. B.; RICARTE, I. L. M. Alinhamentos necessários entre o registro eletrônico de saúde e o sistema de saúde. Informação \& Informação, Londrina, v. 22, n. 3, p. 426-455, 2017. Disponível em: http://www.brapci.inf.br/index.php/res/v/33500. Acesso em: 16 ago. 2020.

GALVÃO, M. C. B.; RICARTE, I. L. M. O prontuário eletrônico do paciente no século XXI: contribuições necessárias da Ciência da Informação. InCID: Revista de Ciência da Informação e Documentação, Ribeirão Preto, v. 2, n. 2, p. 77-100, 2011. Disponível em: http://www.brapci.inf.br/index.php/res/v/39593. Acesso em: 16 ago. 2020.

GALVÃO, M. C. B.; RICARTE, I. L. M. O prontuário eletrônico do paciente em escala nacional. InCID: Revista de Ciência da Informação e Documentação, Ribeirão Preto, v. 10 n. 1, n. 1, p. 244-264, 2019. DOI: 10.11606/issn.2178-2075.v10i1p244-264. Acesso em: 06 ago. 2020.

GALVÃO, M. C. B.; RICARTE, I. L. M. Prontuário do paciente. Rio de Janeiro: Guanabara Koogan, 2012.

HOLLAND, G. A. Information science: an interdisciplinary effort? Journal of Documentation, v. 64, n. 1, p. 7-23, 2008. Disponível em: https://doi.org/10.1108/00220410810844132. Acesso em: 05 ago. 2008.

JAPPE, F. B.; CRUZ, J. A. S. Aplicabilidade da diplomática contemporânea em prontuário de paciente. Ágora, Florianópolis, v. 26, n. 53, p. 286-314, 2016. Disponível em: http://www.brapci.inf.br/index.php/res/v/12927. Acesso em: 16 ago. 2020.

KAWAKAMI, T. T.; LUNARDELLI, R. A.; VECHIATO, F. L. O prontuário eletrônico do paciente na perspectiva das recomendações de usabilidade: proposta de organização da informação. Informação \& Informação, Londrina, v. 22, n. 3, p. 456-483, 2017. Disponível em: http://www.brapci.inf.br/index.php/res/v/32872. Acesso em: 16 ago. 2020. 
LE COADIC, Y. F. A Ciência da Informação. Tradução de Maria Yêda de Filgueiras Gomes. Brasília: Briquet de Lemos/Livros, 1996.

LEITE, J. R.; SOUSA, A. C. M. Práticas arquivísticas no contexto de prontuários médicos: um estudo em unidade de saúde da família. Archeion Online, João Pessoa, v. 3, n. 2, 2015. Disponível em: http://www.brapci.inf.br/index.php/res/v/14931. Acesso em: 16 ago. 2020.

LIMA, M. H. T. F.; SANCHES NETO, A. P. O documento médico na construção do abjeto. In: ENCONTRO NACIONAL DE PESQUISA EM CIÊNCIA DA INFORMAÇÃ̃O, 18., 2017, Marília. [Anais...]. Marília: ANCIB: UNESP, 2017. Disponível em http://www.brapci.inf.br/index.php/res/v/105372. Acesso em: 16 ago. 2020.

LUNARDELLI, R. S. A.; TONELLO, I. M. S.; MOLINA, L. G. A constituição da memória dos procedimentos em saúde no contexto do prontuário eletrônico do paciente. Informação \& Informação, Londrina, v. 19, n. 3, p. 107-124, 2014. Disponível em: http://www.brapci.inf.br/index.php/res/v/33761. Acesso em: 16 ago. 2020.

MENDONÇA, F. M.; CARDOSO, A. M. P.; DRUMOND, E. Ontologia de aplicação no domínio de mortalidade: uma ferramenta de apoio para o preenchimento da declaração de óbitos. Ciência da Informação, Brasília, v. 39, n. 3, 2010. Disponível em: http://www.brapci.inf.br/index.php/res/v/21743. Acesso em: 16 ago. 2020.

MENESES, B. C.; RAULINO NETO, H. F. R.; GIRÃO, I. P. T. Arquitetura da informação: uma ferramenta de mediação e acesso aos prontuários eletrônicos do paciente. Múltiplos Olhares em Ciência da Informação, Belo Horizonte, v. 3, n. 2, 2013. Disponível em: http://www.brapci.inf.br/index.php/res/v/64104. Acesso em: 16 ago. 2020.

MOLINA, L. G.; LUNARDELLI, R. S. A. O prontuário do paciente e os pressupostos arquivísticos: estreitas e profícuas interlocuções. Informação \& Informação, Londrina, v. 15, n. 1, p. 68-84, 2010. Disponível em: http://www.brapci.inf.br/index.php/res/v/33934. Acesso em: 16 ago. 2020.

MORAES, M. F. Requisitos de qualidade e segurança para prontuários do paciente. Informação em Pauta, Fortaleza, v. 3, p. 141-160, 2018. Disponível em:

http://www.periodicos.ufc.br/informacaoempauta/article/view/39722. Acesso em: 02 maio. 2019.

MOTA, F. R. L. Prontuário eletrônico do paciente e o processo de competência informacional. Encontros Bibli: Revista Eletrônica de Biblioteconomia e Ciência da Informação, Florianópolis, v. 11, n. 22, p. 53-70, 2006. Disponível em: http://www.brapci.inf.br/index.php/res/v/31697. Acesso em: 16 ago. 2019

OLIVEIRA, L. A. F.; CUNHA, F. J. A. P. A importância das comissões de avaliação de documentos e de revisão de prontuários em organizações de saúde: um estudo em hospitais.

Informação Arquivística, Rio de Janeiro, v. 3, n. 2, 2014. Disponível em: http://www.brapci.inf.br/index.php/res/v/41566. Acesso em: 16 ago. 2020.

PINTO, V. B. Prontuário eletrônico do paciente: documento técnico de informação e comunicação do domínio da saúde. Encontros Bibli: Revista Eletrônica de Biblioteconomia e Ciência da Informação, Florianópolis, v. 11, n. 21, p. 34-48, 2006. Disponível em: http://www.brapci.inf.br/index.php/res/v/39125. Acesso em: 16 ago. 2020. 
PRODANOV, C. C.; FREITAS, E. C. Metodologia do trabalho científico: métodos e técnicas da pesquisa e do trabalho acadêmico. 2. ed. Novo Hamburgo: Feevale, 2013.

RAMOS, R. O. A preservação da memória da saúde na gestão documental dos arquivos hospitalares. Revista Informação na Sociedade Contemporânea, Natal, v. 2, n. 1, p. 1-13, 2018. Disponível em: http://www.brapci.inf.br/index.php/res/v/70569. Acesso em: 16 ago. 2020.

RICARTE, I. L. M. Percepções de privacidade em sistemas nacionais de prontuários eletrônicos: o caso australiano. Revista Cubana de Información en Ciencias de la Salud, Havana, v. 31, n. 1, e1480, 2020. Disponível em: http://rcics.sld.cu/index.php/acimed/article/view/1480. Acesso em: 06 ago. 2020.

SANCHES NETO, A. P.; LIMA, M. H. T. F. Entre silêncios e sussurros: a questão do acesso à informação sobre o 'louco', uma análise dos prontuários do hospital psiquiátrico de jurujuba. Logeion: Filosofia da Informação, [s. l.], v. 3, n. 1, p. 64-79, 2016. Disponível em: http://www.brapci.inf.br/index.php/res/v/32965. Acesso em: 16 ago. 2020.

SANCHES NETO, A. P.; LIMA, M. H. T. F. Uma proposta de análise epistemológica: observando o documento médico. In: ENCONTRO NACIONAL DE PESQUISA EM CIÊNCIA DA INFORMAÇÃO, 18., 2017, Marília. [Anais...]. Marília: ANCIB: UNESP, 2017. Disponível em: http://www.brapci.inf.br/index.php/res/v/105366. Acesso em: 16 ago. 2020.

SANTOS, B. R. P. D.; VITORIANO, M. C. C. P.; DAMIAN, I. P. M. A gestão da informação orgânica e a gestão documental no contexto do prontuário do paciente de unidades básicas de saúde. Ponto de Acesso, Salvador, v. 13, n. 2, p. 202-222, 2019. Disponível em: https://portalseer.ufba.br/index.php/revistaici/article/view/26063. Acesso em: 06 ago. 2020.

SANTOS, B. R. P.; DAMIAN, I. P. M. Análise da competência em informação mediante a transição do prontuário físico para o eletrônico. Revista Cubana de Información em Ciencias de la Salud, Havana, v. 28, n. 4, 2017. Disponível em:

http://www.brapci.inf.br/index.php/res/v/74565. Acesso em: 16 ago. 2020.

SANTOS, J. M. P. Organização da informação na saúde: uma análise dos padrões de metadados brasileiros. Cadernos BAD, Lisboa, n. 1, p. 227-233, 2018. Disponível em:

http://www.brapci.inf.br/index.php/res/v/110049. Acesso em: 02 maio. 2019.

SARACEVIC, T. A natureza interdisciplinar da Ciência da Informação. Ciência da Informação, Brasília, v. 24, n. 1, p. 1-9, 1995. Disponível em: http://revista.ibict.br/ciinf/article/view/608. Acesso em: 03 nov. 2020.

SARACEVIC, T. Ciência da Informação: origem, evolução e relações. Perspectivas em Ciência da Informação, Belo Horizonte, v. 1, n. 1, p. 41-62, jan./jun. 1996.

SIEBRA, S. A. Curadoria digital: uma área em expansão. Archeion Online, v. 6, n. 2, 2019. Disponível em: https://periodicos.ufpb.br/ojs/index.php/archeion/article/view/47089. Acesso em: 06 ago. 2020.

SILVA, M. P. B. E.; SOUSA, M. R. F. PINTO, V. B.; Pensando a arquitetura da informação pervasiva aplicada ao registro eletrônico de saúde. In: ENCONTRO NACIONAL DE PESQUISA EM CIÊNCIA DA INFORMAÇÃO, 19., 2018, Londrina. [Anais...]. Londrina: ANCIB: UEL, 2018. Disponível em: http://www.brapci.inf.br/index.php/res/v/103470. Acesso em: 16 ago. 2020. 
SILVA, M. V. T. Gestão documental no contexto hospitalar maria. Revista Brasileira de Biblioteconomia e Documentação, São Paulo, v. 12, n. especial, p. 266-269, 2016. Disponível em: http://www.brapci.inf.br/index.php/res/v/2612. Acesso em: 16 ago. 2020.

SOARES, J. M. L.; BORGES, R. R.; PINTO, V. B. Mapeamento e análise dos conceitos de prontuários do paciente nefropata visando a categorização e representação da informação. Biblionline, ed. especial: XXXIII Encontro Nacional de Estudantes de Biblioteconomia, Documentação, Ciência da Informação e Gestão, 2010. Disponível em: http://www.brapci.inf.br/index.php/res/v/100238. Acesso em: 16 ago. 2020.

SOUZA, A. D.; ALMEIDA, M. B. Termos usados na prática clínica e sua conexão com terminologias padronizadas. Múltiplos Olhares em Ciência da Informação, Belo Horizonte, v. 9, n. 2, 2019. Disponível em: http://hdl.handle.net/20.500.11959/brapci/137124. Acesso em: 06 ago. 2020.

SOUZA, A. D.; SOUZA, R. F. P. Prontuário eletrônico do paciente: estudo de práticas em hospitais universitários da região sudeste do Brasil. In: ENCONTRO NACIONAL DE PESQUISA EM CIÊNCIA DA INFORMAÇÃO, 19., 2018, Londrina. [Anais...]. Londrina: ANCIB: UEL, 2018. Disponível em: http://www.brapci.inf.br/index.php/res/v/102009. Acesso em: 16 ago. 2020.

TEIXEIRA, L. M. D.; ALMEIDA, M. B. Aspectos ontológicos e epistemológicos em terminologias clínicas: em busca de interoperabilidade semântica no ambiente clínico. Encontros Bibli: Revista Eletrônica de Biblioteconomia e Ciência da Informação, Florianópolis, v. 24, n. 55, p. 1-21, 2019a. Disponível em: https://periodicos.ufsc.br/index.php/eb/article/view/15182924.2019.e57996. Acesso em: 06 ago. 2020.

TEIXEIRA, L. M. D.; ALMEIDA, M. B. Princípios ontológicos no suporte a terminologias clínicas: método e ontologia para reorganização da classificação internacional de doenças. Ciência da Informação, Brasília, v. 48, n. 1, 2019b. Disponível em: http://hdl.handle.net/20.500.11959/brapci/110941. Acesso em: 06 ago. 2020.

TONELLO, I. M. S.; NUNES, R. M. S.; PANARO, A. P. Prontuário do paciente: a questão do sigilo e a lei de acesso à informação. Informação \& Informação, Londrina, v. 18, n. 2, p. 193210, 2013. Disponível em: http://www.brapci.inf.br/index.php/res/v/34850. Acesso em: 16 ago. 2020.

ZILLI JÚNIOR, P. V. Z.; PINTO, A. L. Aplicação de uma metodologia e mensuração do processo de digitalização: estudo a partir de prontuários de pacientes. Ágora, Florianópolis, v. 24, n. 48, 2014. Disponível em: http://www.brapci.inf.br/index.php/res/v/14049. Acesso em: 16 ago. 2020. 